\title{
Quantum leadership for co-development in private universities
}

\author{
Rafael Paz ${ }^{\# 1}$, Raúl J. Martelo ${ }^{* 2}$, Diofanor Acevedo ${ }^{* 3}$ \\ \# Independent researcher \\ ${ }^{1}$ rafaelpaz1958@hotmail.com \\ * Faculty of Engineering, Faculty of Economics Sciences \\ University of Cartagena, Cartagena, Bolívar, Colombia. \\ 2 rmartelog1@unicartagena.edu.co \\ 3 diofanor3000@gmail.com
}

\begin{abstract}
The present research aimed to analyze the quantum leadership for the co-development of private universities. The type of research was descriptive, analytical, with non-experimental design, descriptive cross-sectional. Inferential statistics were used for data processing. The results showed that the leader has the creativity, experience, learning, action and assumes the condition of quantum leadership giving greater importance to total acceptance, presence and ultimately talent. The most used co-development is the internal, the leader presents the theme, puts the competition in practice, allows reflection and self-evaluation, promotes the design of an action plan, and monitors the training received, which Constitutes a highly utilized experience within these institutions of higher education. It was recommended to raise the use of creativity and increase the talent of its quantum leaders in codevelopment and ultimately to increase the use of open co-development.
\end{abstract}

Keyword - Skills, Competencies, Creativity, Knowledge, Managerial approaches, Organizational management

\section{INTRODUCTION}

In organizational management, strategic thinking is one of the main skills that every person must develop, not only professionally, but also personally, since it allows the strengthening of organizational management, which is fundamental in the current times, where it requires flexible organizations that respond to the demands of the competitive market that demands the applicability of managerial approaches to the information and knowledge society [1]. In that order of ideas, leadership is one of the management tools used to face the changes produced by the fluctuations that are generated by the effects of the political, economic and social crisis that affect organizations. It is a fundamental phenomenon in the history of human society and therefore in the development and durability of social organizations [2].

It has been found that the eminently relational and interconnected nature of all the components of the Universe apply to people and, naturally, to organizations [3]. From this theory, new tendencies of leadership are born, which are not constituted by chance, but respond to a whole movement that puts man at the center of the world stage as an integral being and not as an object of manipulation or control [4]. The quantum leadership, is the art of changing a person to drive others to the evolution and transformation that is generated by being part of a portion of the whole, acts, thoughts and intentions are interwoven with the whole [5]. It is one of many skills that a manager must possess to make his work effective, it allows him to expand in himself, in order to achieve the objectives that the organization draws and expand his staff to optimally reach the established business goals.

That is why the training plans have become partners to achieve these goals, in which not only the worker is trained, but a solid internal knowledge base is assured in the face of changes in the environment [6]. One of the focuses on the concept of training is co-development, this is concrete actions that a subject participates together in a training activity guided by an instructor with the purpose of perfecting their intellectual faculties through the explanation of concepts, exercises, examples among others [7]. The review of related articles allows to have a clear vision of the landscape of how quantum leadership is located and co-development in the field of administration among others. Within these articles is an essay by [8] in which they focus on the specific leadership behaviors and generic leadership functions they adopt, as well as offering an integrated vision of the impact of directed and distributed leadership in the behavior and results of organizational change.

[9] Present a document, in which they describe a way of thinking about organizations and administration that has recently gained ground among theorists and professionals, this way of thinking is called the quantum perspective and is often presented as a replacement of the Newtonian perspective. Similarly, in [10], which address aspects of quantum mechanics and relate them to acting, acting and influencing managers about people and the future. The above, among other details, describes a quantum thought of leadership which exists under the conception of internal change and conceives the evolution of it, so as to take it on levels that consent to assume the transformations of the leader, from its inner part of its led effectively. 
In relation to co-development, [11] is presented, with an article that suggests important aspects of the transformations that come from the use of co-development as a training mechanism, based on the intentional use made of the transfers of competences initially produced by the migrations from one country to another.

Because of the aforementioned, the organizations worldwide, given the changing conditions of the environment, is called to consider the quantum leadership for co-development, the stages, the condition of quantum leadership, as well as the types and steps of co-development, the which allow generating the necessary information to reach the desired performance standards and the goals established in an optimal way. Venezuela does not depart from this reality, the situation that many of its organizations, especially those in the field of higher education, require them to resort to theoretical models generated from the study of the competencies that their managers must have in direct contact and cash with your staff. Likewise, there are difficulties in the use of quantum leadership, a situation that is manifest in the type of co-development used by the quantum leader in the exercise of his functions given the relative use of internal co-development in the training of the teaching staff under his charge, bringing as consequences, a marked disorientation of the teachers, related to the development opportunities offered by the universities and the immediate environment, to promote the progressive and formal academic formation of their academic staff at a given moment.

Due to the problems related to the stages, the condition of quantum leadership and the mode, types, steps and method of co-development, make necessary the exhaustive study of quantum leadership for co-development in private universities, to correct the problems that affect them and in this way reach the desired performance standards and the established goals in an effective way.

\section{MATERIALS AND METHODS}

The present investigation was descriptive in the field. Descriptive because it was based on observation and description of facts as they were presented [12]; and the field, since data collection was done within the institutions under study, from which real information provided by private universities was obtained [13].

Regarding the design, the research was non-experimental in that studied phenomena were observed as they occurred in their natural context, to be analyzed later; it was characterized as cross-sectional - descriptive, because the necessary data were collected at a specific time and time [14], in order to analyze the quantum leadership for co-development in private universities.

\section{A. Literature review}

Previous studies were found, which supported the theories that allowed defining and operationalizing the variables quantum leadership (Fig. 1) and co-development (Fig. 2), together with its components, factors and authors for sustenance.

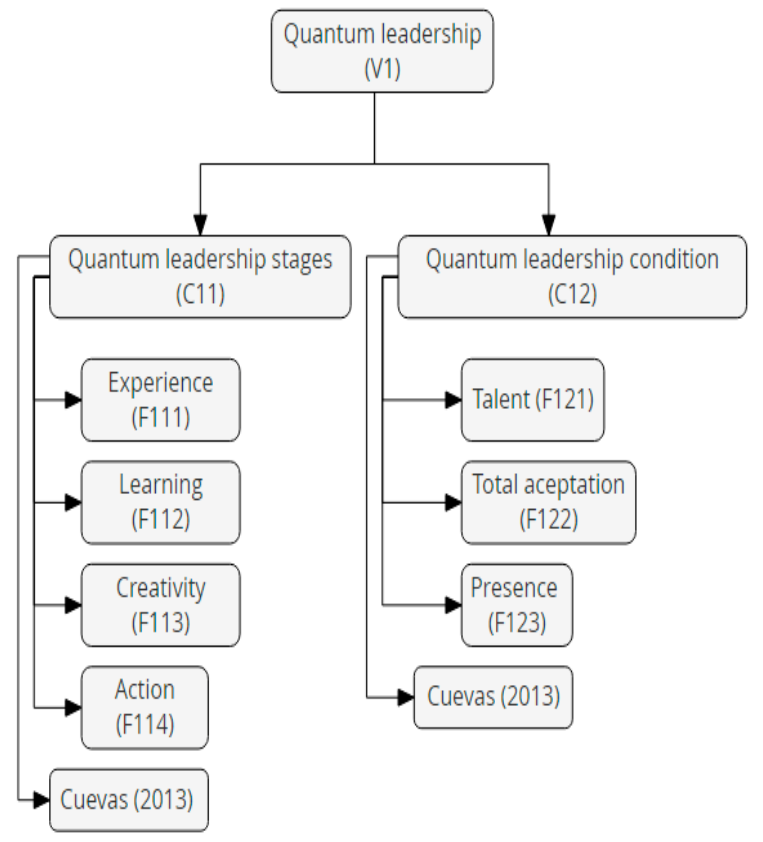

Fig. 1: Variable Quantum Leadership (V1) with components (C1x), factors (F1xy) and authors. 


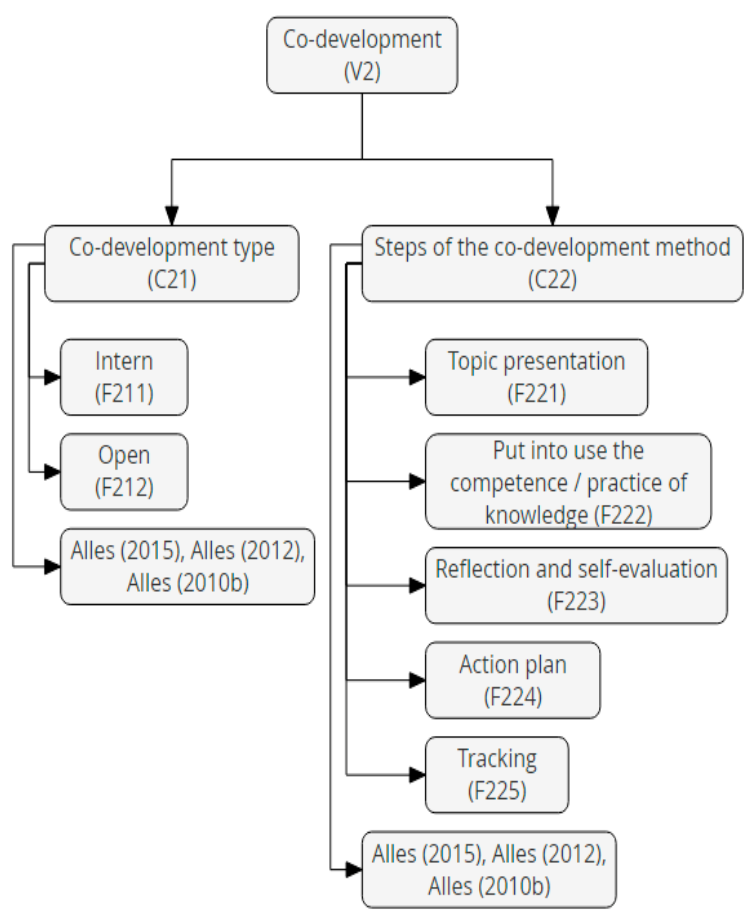

Fig. 2: Variable Quantum Leadership (V2) with components (C2x), factors (F2xy) and authors.

\section{B. Determination of population and sample}

The population and sample of actors in the analysis unit were determined, in this case deans and school directors belonging to the private Dr. Rafael Belloso Chacín University and the Dr. José Gregorio Hernández University.

The population was finite, accessed and found to be made up of less than 100,000 units. Then, the sample was defined based on the following inclusion criteria:

a) Deans and school directors as holders with appointment signed by the rectory of their university

b) Work during the school year 2016

c) Knowledge of the work environment

d) Willingness to respond to the instrument

In this sense, the sample of the private universities and the informant units were structured in the way that can be observed in Table 1.

TABLE 1. Informant subjects

\begin{tabular}{|c|c|c|c|c|}
\hline \multirow{2}{*}{$\mathbf{N}^{\mathbf{*}}$} & Universities & \multicolumn{2}{|c|}{ Charges } & \multirow{2}{*}{ Quantity } \\
\cline { 3 - 4 } & & Deans & School Directors & \\
\hline 1 & Dr. Rafael Belloso Chacín University & 5 & 9 & 14 \\
\hline 2 & Dr. José Gregorio Hernández University & 3 & 3 & 6 \\
\hline \multicolumn{2}{|c|}{ Total } & 8 & 12 & 20 \\
\hline
\end{tabular}

\section{Technique and data collection instrument}

For data collection, the technique of direct observation and questionnaire-type survey was selected, which allowed to receive data from the subjects belonging to the study population. As an instrument, a 42-item questionnaire was used, based on the Likert scale (Table 2).

TABLE 2. Questionnaire answers

\begin{tabular}{|c|c|}
\hline Answers & Weighing \\
\hline Totally agree & 5 \\
\hline Agree & 4 \\
\hline Neither agree nor disagree & 3 \\
\hline In disagreement & 2 \\
\hline Totally disagree & 1 \\
\hline
\end{tabular}




\section{Design, validity and reliability of the instrument gather information}

When considering benefits such as those provided by the questionnaires in the data collection, this research used one based on the Likert scale (Table 3), which was provided directly to the respondent to respond under the guidelines and instructions referred to in it.

TABLE 3. Questionnaire answer options

\begin{tabular}{|c|c|c|}
\hline Option & Acronym & Score \\
\hline Totally agree & TA & 5 \\
\hline Agree & DA & 4 \\
\hline Medium agree & MA & 3 \\
\hline Neither agree nor disagree & NA/ND & 2 \\
\hline Strongly disagree & MD & 1 \\
\hline
\end{tabular}

The validity of the instrument was obtained through the judgment of nine (9) expert doctors of the universities, who were in charge of evaluating the correspondence between items and objectives, components and established factors, by means of the determination of the relevance and coherence of the research. In order to carry out the procedure of validity and reliability, a format was elaborated which presents a set of instructions that guided the experts in the evaluation of the same, in order to obtain from them their opinions and valuations on the items.

For the reliability of the instrument the Cronbach's Alpha coefficient (Formula 1) was used, which, according to [15] is the best choice among all published reliability coefficients. In fact, this method requires a single administration, which was applied to a similar population.

$$
r_{t t}=\frac{K}{K-1}\left(1-\frac{\sum S_{i}^{2}}{S_{t}^{2}}\right)
$$

Wherein:

$\mathrm{K}=$ Number of items that the instrument has

$\mathrm{r}_{\mathrm{tt}}=$ Reliability coefficient

$\mathrm{S}_{\mathrm{i}}^{2}=$ Variance of the scores of each item

$\mathrm{S}_{\mathrm{t}}{ }^{2}=$ Variance of totals

Substituting the values obtained from the tabulating of the pilot test, a reliability of 0.91 was obtained, considered as very high, which allowed the definitive application of the instrument.

\section{E. Application of the instrument and analysis of results}

For the parametric analysis, the $\mathrm{T}$ Student test was used for independent samples between components. Likewise, the averages obtained were used according to the greater tendency in the answers, also showing the arithmetic average in order to categorize the results based on a scale of analysis that has been designed for the purpose of this study, which is observed in the Table 4.

TABLE 4. Scale of categorization of values for the analysis of data

\begin{tabular}{|c|c|c|c|}
\hline Response alternative & Interval & Range & Analysis category \\
\hline Totally agree & $4.20-5.00$ & 5 & Highly realized \\
\hline Agree & $3.40-4.19$ & 4 & Lightly realized \\
\hline Neither agree nor disagree & $2.60-3.39$ & 3 & Medically realized \\
\hline In disagreement & $1.80-2.59$ & 2 & Little realized \\
\hline Totally disagree & $1.00-1.79$ & 1 & Unrealized \\
\hline
\end{tabular}

We analyzed the data collected to achieve the research objective, which were processed through inferential statistics, including measures of variability; parametric methods for the comparison of means with the weighted ranges to determine the degree of presence of the factors, components and variables. Likewise, the Analysis of Variance (ANOVA) technique and Tukey Post Hoc Test was used for the study of positioning, as well as the subsets established from the significant differences between each of the factors, to show the high means in contrast with the low. 


\section{III.RESULTS}

\section{A. V1 Analysis}

The level of significance of the components was determined from their factors, by means of ANOVA (Table $5)$.

TABLE 5. Significance level for V1 components

\begin{tabular}{|c|c|c|c|c|c|c|}
\hline Comp. & & $\begin{array}{c}\text { Sum of } \\
\text { squares }\end{array}$ & GL & \multicolumn{1}{|c|}{$\begin{array}{c}\text { Root mean } \\
\text { square }\end{array}$} & F & Sig. \\
\hline \multirow{3}{*}{ C11 } & Inter-groups & .150 & 3 & .050 & .196 & .899 \\
\cline { 2 - 7 } & Intra-groups & 19.400 & 76 & .255 & & \\
\cline { 2 - 7 } & Total & 19.550 & 79 & \multicolumn{3}{|c|}{} \\
\hline \multirow{3}{*}{ C12 } & Inter-groups & .133 & 2 & .067 & .288 & .751 \\
\cline { 2 - 7 } & Intra-groups & 13.200 & 57 & .232 & & \\
\cline { 2 - 7 } & Total & 13.300 & 59 & \multicolumn{4}{|c}{} \\
\hline
\end{tabular}

The meanings found by each component indicate that for $\mathrm{C} 11$ and $\mathrm{C} 12$ there are not significant differences between the compared factors, so that all have the same degree of presence within the indicated component.

Then, the smallest difference between factors was detected using the Tukey Post Hoc multiple range test, which also highlights the homoscedasticity of their variances (Table 6) and shows the means for groups in homogeneous subsets (harmonic mean equal to 20).

TABLE 6. ANOVA of a factor, homogeneous subsets

\begin{tabular}{|c|c|c|}
\hline \multirow{3}{*}{ Comp. } & \multirow{2}{*}{ Factor } & Alpha Subset $=\mathbf{0 . 0 5}$ and $\mathbf{N}=\mathbf{2 0}$ \\
\cline { 3 - 3 } & & $\mathbf{1}$ \\
\hline \multirow{4}{*}{ C11 } & F113 & 3.6000 \\
\cline { 2 - 3 } & F111 & 3.7000 \\
\cline { 2 - 3 } & F112 & 3.7000 \\
\cline { 2 - 3 } & F114 & 3.7000 \\
\cline { 2 - 3 } & Sig. & .923 \\
\hline \multirow{4}{*}{ C12 } & F123 & 3.6000 \\
\cline { 2 - 3 } & F121 & 3.7000 \\
\cline { 2 - 3 } & F122 & 3.7000 \\
\cline { 2 - 3 } & Sig. & .789 \\
\hline
\end{tabular}

From Table 6, it can be deduced that the test placed a subset of both components, based on the similarity and differences in behavior between their means, and also placed all the factors in the lightly realized analysis category.

With the established results, the analysis of each component is detailed below.

\section{1) Analysis of component "stages of quantum leadership"}

The above results reveal a slight coincidence in terms of the criteria expressed by the reporting subjects, who assume that the stages of quantum leadership are slightly feasible in the context of private universities, which coincides with the statements made by [5], by stating that quantum leaders should expand and evolve in four stages, namely: experience, creativity, learning and action, which once covered, allow the leader to discover a clear, powerful and simple way to direct their attention and evolve in each stage. They also agree with the approach of [10], which address aspects of quantum mechanics, such as the consideration that everything in the world is part of an interrelated and complex whole in which each part interacts with all others, related to the performance of the manager, it makes me act responsibly and influence all people and the future.

In this sense, creativity is of great impact in private universities, because it is necessary for the different activities or tasks that are developed in the practice of quantum leadership. The leader shows creativity when putting his ideas, generates the possibilities to transcend problematic situations and gives himself time to exercise his imagination creating analog thoughts for his followers. The above supports it [5] by stating that if the leader does not focus his attention and energy on generating new ideas, he will be limited to always do the same, for which the leader must invest attention, time and energy in exercising creativity, thus developing creative environments, exercising imagination and analogical thoughts. 
In terms of experience, the leader in his area of work, becomes an apprentice, to learn from the experiences of his followers, part of their experience to break the boundaries that allow them to grow as a person, and reach the expansion as a person. In this regard, [5] states that from experience, all possibilities are created. Experiencing learns, generates knowledge, breaks boundaries, grows as a person and as a leader. In terms of learning, the leader seeks that his followers learn from their experiences, in order to transcend as a person, induces them to achieve their own learning and allows them to free themselves, breaking with the borders of the world in which they find themselves. This theory is supported by what was said by [16], when they assert that learning usually takes place in stages. A stage concludes when the cognitive system assumes the new competence or ability and is acquired as a new automatic habit.

In relation to the action, the leader summarizes his ideas when guiding the actions of his disciples, makes decisions about the actions that he must execute to achieve a change and it is clear from his comfort state for it. In this regard [5] affirms that in quantum leadership new ideas and dreams must be turned into tangible realities; manifest, specify, build another reality or experience.

\section{2) Analysis of component "condition of quantum leadership"}

The results coincide with the criteria expressed by the reporting subjects, who assume that the quantum leadership status is slightly achievable in the private universities, which coincides with what was stated by [17], who affirms that, a good leader must create opportunities for self-exploration, learning, action, establishes a clear direction and keeps people under high standards. Similarly, the condition "presence" reveals a slight importance in private universities, because it was considered essential for the different activities or tasks that are developed in the practice of quantum leadership. In this sense the leader looks at his followers with confidence in his talent, he observes them accepting and respecting his learning times. They also show that the leader in their area of work assumes that their followers have the ability to move forward and recognizes that talent is contained in each person. In this regard [18] states that to achieve the status of quantum leadership, it is assumed that followers can have the strength to compete, commit, have responsibility and be independent, in addition to assuming the potential of the leader to share the leadership.

Regarding the total acceptance, the results allow to state that the leader in his area of work, considers that the condition of quantum leadership is a total acceptance of the person being guided, and that also implies "detachment". Similarly, the results show that the leader feels respect for the people he or she guides, recognizes that each of their followers has their time (always different) and agrees that each of them has a way of learning. This coincides with that formulated by [18], were based on the uncertainty principle, the quantum leader is defined as someone who is trained with the uncertainties, probabilities and complexity.

\section{3) General results of $V 1$}

The above results reveal a slight coincidence in terms of the behavior assumed by the subjects in the environment under investigation is explained (Table 7).

TABLE 7. V1 Group statistics, $\mathrm{T}$ test for independent samples

\begin{tabular}{|c|c|c|c|c|}
\hline Factor & $\mathbf{N}$ & Average & Typ. deviation & Typ. Err. of average \\
\hline C11 & 20 & 3.6075 & 0.2872 & 0.1436 \\
\hline C12 & 20 & 3.6400 & 0.6557 & 0.3786 \\
\hline
\end{tabular}

From the results presented, it is observed that both averages were placed in a lightly realized category, furthermore, it was evidence that there are no major differences between the criteria of the V1 components, therefore the difference between means and variances for $\mathrm{C} 11$ and $\mathrm{C} 12$ is very significant.

The aforementioned, indicates that the stages of leadership and the quantum leadership condition are effective and do not differ significantly with respect to their means. Similarly, he warns that in the private universities of the Maracaibo municipality of Zulia state, the leader in his area of work uses the stages of quantum leadership and is in the condition of quantum leadership, when related to his followers. Likewise, the scores of the two components deviate from the average on average 0.35 units of the scale, which exposes a low dispersion in the data, reflecting with this a high level of reliability of the respondents' responses.

The quantum leadership variable was located with an average of 4.64 points, which places it in the category highly realized. The score deviates from the average on average 0.35 units of the scale established in the scale, which shows a low dispersion of the data. In this regard, the variability evidenced in the sample distribution, indicates that there is a homogeneity of their data in correspondence with the behaviors assumed by the subjects that characterize the population. Starting from the previous assumptions, the two components that structure the variable quantum leadership, stood out with a positive tendency given the opinion of the reporting subjects. Based on the results found, the strengths found in the private universities of the Maracaibo municipality of Zulia state are effective to implement actions that maintain or leverage the attitudinal use of quantum leadership, which will result in improvements for all the members of these institutions. 
Table 8 shows the behavior of the samples for the quantum leadership variable. The Levene statistic and its significance value indicate the equality criterion of the variances for this variable. The confidence interval is also presented, which includes the difference of means and, given the difference of these, it is within the confidence interval, which allows accepting that the means of both samples are statistically equal, that is, that there are no differences between the two samples in relation to their means.

TABLE 8. Levene and T Student tests for two samples independent of V1

\begin{tabular}{|c|c|c|c|c|c|c|c|c|c|}
\hline & \multicolumn{2}{|c|}{$\begin{array}{c}\text { Levene tests for } \\
\text { equality of variances }\end{array}$} & \multicolumn{7}{|c|}{ T test for equality of means } \\
\hline & \multirow[t]{2}{*}{$\mathbf{F}$} & \multirow[t]{2}{*}{ Sig. } & \multirow[t]{2}{*}{$\mathbf{T}$} & \multirow[t]{2}{*}{ Gl } & \multirow{2}{*}{$\begin{array}{l}\text { Sig. } \\
\text { (bilat.) }\end{array}$} & \multirow[t]{2}{*}{ Dx } & \multirow[t]{2}{*}{ EDx } & \multicolumn{2}{|c|}{$95 \%$ conf. inter. to dif. } \\
\hline & & & & & & & & Inf. & Sup. \\
\hline $\mathrm{AV}$ & 1.989 & .218 & -.904 & 5 & .407 & -.03250 & 0.3595 & -.12490 & .05990 \\
\hline NAV & & & -.803 & 2.581 & .489 & -.03250 & 0.4049 & -.17403 & .10903 \\
\hline
\end{tabular}

Wherein:

$\mathrm{AV}$ : Equal variances have been assumed.

NAV: No equal variances have been assumed.

Dx: Difference of means.

EDx: Typical error of the difference.

\section{B. V2 Analysis}

To characterize C21 in the universities analyzed, it was developed on the basis of the two factors (internal and open) that define the concepts corresponding to it, then the results are presented in Table 9, in which the assumed behavior is exposed by the informant subjects in the environment under study.

TABLE 9. T test for independent samples in C21

\begin{tabular}{|c|c|c|c|c|}
\hline Factor & $\mathbf{N}$ & Average & Typ. deviation & Typ. Err. of average \\
\hline F211 & 20 & 3.4500 & .51042 & .11413 \\
\hline F212 & 20 & 3.0500 & .75915 & .16975 \\
\hline
\end{tabular}

From the results, it was obtained that F211 and F212 showed differences between the criteria of the factors of the component, thus by the values ' $t$ ' obtained: 0.36 for F211 (significant value - significant difference) and 0.99 (least significant value - very significant difference). With the aforementioned, said factors were placed in the slightly performed and moderately performed categories respectively.

In Table 10, the behavior of the samples for the C21 component is observed, the statistic of Levene assumes and its value of statistical significance, which allow assuming the criterion of equality of the variances. Similarly, the table presents the confidence interval, and given the difference between the two means $(-0.4)$, it is within the confidence interval, which allows accepting that the means of both samples are statistically equal, that is, there are no differences between the two samples as regards their means.

TABLE 10. Levene test and T Student test for two independent samples in C21

\begin{tabular}{|c|c|c|c|c|c|c|c|c|c|}
\hline & \multicolumn{3}{|c|}{$\begin{array}{c}\text { Levene tests for } \\
\text { equality of variances }\end{array}$} & \multicolumn{9}{|c|}{ T test for equality of means } \\
\cline { 2 - 9 } & F & Sig. & T & Gl & $\begin{array}{c}\text { Sig. } \\
\text { (bilat.) }\end{array}$ & Dx & EDx & \multicolumn{2}{|c|}{ 95\% conf. inter. to dif. } \\
\cline { 2 - 10 } & & .495 & 1.955 & 38 & 0.58 & .400 & .20455 & -.01410 & .81410 \\
\hline AV & .475 & & 1.955 & 33.263 & 0.59 & .400 & .20455 & -.01604 & .81604 \\
\hline NAV & & & & &
\end{tabular}

Wherein:

AV: Equal variances have been assumed.

NAV: No equal variances have been assumed.

Dx: Difference of means.

EDx: Typical error of the difference.

In order to determine C22 in the analyzed universities, by using ANOVA one can observe the significance obtained by the said factors, which obtained a level of significance with which it can be affirmed that there are insignificant differences between the compared factors, so that all they have the same degree of presence within the indicated component (Table 11). 
TABLE 11. Level of significance in C22

\begin{tabular}{|l|l|l|l|l|l|}
\hline & Sum of squares & GL & Root mean square & F & Sig. \\
\hline Inter-groups & .660 & 4 & .1655 & .365 & .833 \\
\hline Intra-groups & 42.900 & 95 & .452 & & \\
\hline Total & 43.560 & 99 & & & \\
\hline
\end{tabular}

Then, the comparison of the Tukey Post Hoc multiple range test reveals the little difference between the various factors of the $\mathrm{C} 22$ component and the variable V2, likewise highlights the homoscedasticity of the variances between the factors (with harmonic mean $\mathrm{N}$ of 20.000) (Table 12).

TABLE 12. ANOVA of a factor homogeneous subsets in C22

\begin{tabular}{|c|c|}
\hline \multirow{2}{*}{ Factor } & Alpha subset $\mathbf{0 . 0 5}$ \\
\cline { 2 - 2 } & $\mathbf{1}$ \\
\hline F223 & 3.3000 \\
\hline F225 & 3.3000 \\
\hline F224 & 3.3500 \\
\hline F222 & 3.4500 \\
\hline F221 & 3.5000 \\
\hline Sig. & .880 \\
\hline
\end{tabular}

Tukey's multiple-rank test placed a subset, based on the similarity and behavioral differences between its means.

\section{1) Analysis of component "type of co-development"}

The results indicate that internal and open co-development are effective and differ significantly with respect to their means, that is to say, that in the universities analyzed, the leader in their area of work uses internal codevelopment to a greater extent and, to a lesser extent, open co-development, when he trains his followers. Likewise, the scores of the two factors deviate from the average on average 0.36 units of the scale, which exposes a low dispersion in the data, for the internal co-development and higher for the open co-development, thus reflecting an average level of reliability of the responses of the reporting subjects. In this order of ideas, the internal co-development component was located with an average of 4.17 points, a rating that places it in the lightly realized category. Similarly, the score deviates from the average on average 0.36 units of the scale established in the scale, which shows a low dispersion of the data. In this regard, the variability evidenced in the sample distribution, indicates that there is a homogeneity of their data in correspondence with the behaviors assumed by the subjects that characterize the population in the organizational contexts studied.

The two factors that structure the type component of co-development; internal co-development and open codevelopment, stood out with a positive tendency referring to internal co-development, but less in relation to open co-development due to the opinion of the reporting subjects. This result is partially related to [7], when it states that co-development is a learning method, and can have different variants: being internal and of a particular organization, external with participants from different organizations. Based on the results found, the strengths found in the private universities of the Maracaibo municipality of Zulia state are effective to implement actions that are in function of maintaining the use of internal co-development and leveraging the use of open co-development, which will translate into improvements for training all members of these institutions.

\section{2) Analysis of component "steps of the co-development method"}

The results show a marked coincidence in relation to the criteria exhibited by the informant subjects, who assume that the steps of the co-development method are highly feasible in the field of private universities, which coincides with that indicated by [7], who states that co-development is a learning method, and can have different variants: being internal and of a particular organization, external with participants from different organizations. In this regard, reflection and self-evaluation, as well as the monitoring used in the contexts studied, are of great importance for private universities, because they are indispensable when developing the activities or tasks involved in co-development. In this sense, the leader leads followers to the reflection of the competence that they will receive, they take them to take true consciousness with respect to the competition as well as the knowledge and they administer them a test with questions about co-development.

The above results are consistent with the approach presented by [7], when he states that the co-development workshop is designed with this instance in which, under the name of Self-evaluation, the participant is administered a test with questions, for which offer response options from which you must choose only one. As for monitoring, the results show that the leader in these institutions, leads to the use of good practice selfdevelopment of their followers, keeps track of everything taught in the classroom workshops, especially the self 
and complete the method of co-development putting into operation all the roads in the development of knowledge as well as the competences, at the same time. The aforementioned, coincides with the outline presented by Alles (2010b), with reference to the fifth step that implies the follow-up of everything that was done during the face-to-face workshop and especially, the self-development.

As for the action plan, the results show that the leader in his area of work, carries out an action plan during the co-development workshops, and leads the leaders to draw up an action plan and leads them to selfdevelopment as a way of concrete experience for learning. Considering these considerations, these results are consistent with what was formulated by the author Alles (2010b) when stating that the action plan is a final step of the co-development workshop, which is necessary to achieve the acquisition or development of both knowledge and of a competition. In terms of putting competition / knowledge into play, the leader in his area of work, initiates, co-development proposing activities that involve the putting into play of competencies such as knowledge as appropriate, allows reflections on the way in which the subject It deals with co-development and makes learning to grow by adding new actions on the subject in particular. In this regard, Alles (2010b) affirms that learning / development is verified when a person can perform the respective action, when applying knowledge or demonstrate behavior in their performance that corroborates the implementation of the competition, if this is the case.

Regarding the factor "present the theme", the leader seeks to externalize the meaning that has for the institution the issue to be addressed in co-development, devotes part of the co-development activity to explain what is the definition of the competence to develop for this organization in particular, and presents the topic to be dealt with, defining its meaning for the institution. These results agree with the silver plated by Alles (2010b) when affirming that the competencies are defined to the measure; therefore, the definitions may vary from one organization, for that reason the leader must properly clarify the terms or issues that he wishes to develop because the meaning of the same varies between the institutions.

\section{3) General results of V2}

The general results of V2 (Table 13), expose the behavior assumed by the subjects in the research environment.

TABLE 13. T test for independent samples

\begin{tabular}{|c|c|c|c|c|}
\hline Factor & $\mathbf{N}$ & Average & Typ. deviation & Typ. Err. of average \\
\hline Present the topic & 20 & 3.2333 & .24833 & .10138 \\
\hline Put competition to use & 20 & 3.3240 & .07956 & .03558 \\
\hline
\end{tabular}

Table 13 shows the general data obtained in the processing of V2, where the $\mathrm{T}$ test for independent samples yielded two averages located in the moderately performed category. After processing the data, since the value of ' $t$ ' is significant, it is found that there are no major differences between the criteria of the components of V2. Therefore, the difference between means and variances for C21 and C22 is very significant, which indicates that these components are effective and do not differ significantly with respect to their means. In this sense, the foregoing points out that in the private universities of the Maracaibo municipality of Zulia state, the leader in their area of work uses the types of co-development and the steps of co-development during the formation of their followers.

The scores of the two components deviate from the average on average 0.68 units of the scale, which exposes a low dispersion of data that reflects a high level of reliability in the responses of the reporting subjects. The average of the co-development variable causes it to be placed in the category medically realized. Similarly, the score deviates from the average around 0.68 units of the scale established in the scale, which shows a low dispersion of the data. In this regard, the variability evidenced in the sample distribution indicates that there is a homogeneity of their data in correspondence with the behaviors assumed by the subjects that identify the population in the contexts studied.

The two components that structure the variable co-development, stood out with a positive tendency given the opinion of the reporting subjects. In accordance with Alles (2010b), co-development is defined as the concrete actions that the subject who attends a training activity guided by an instructor in order to develop their skills and / or knowledge jointly. The results show that the strengths in the private universities of the Maracaibo municipality of Zulia state are effective to implement actions that are in function of maintaining the use of codevelopment, which would result in improvements for all members of private universities.

In Table 14, the behavior of the samples for the quantum leadership variable is observed, in that order it is evidenced that the Levene statistic and its value of statistical significance, which allows assuming the equality criterion of the variances for this variable. 
TABLE 14. Levene test and T student test for two independent samples, variable V1

\begin{tabular}{|c|c|c|c|c|c|c|c|c|c|}
\hline & \multicolumn{2}{|c|}{$\begin{array}{l}\text { Levene tests for } \\
\text { equality of variances }\end{array}$} & \multicolumn{7}{|c|}{$T$ test for equality of means } \\
\hline & \multirow{2}{*}{$\mathbf{F}$} & \multirow{2}{*}{ Sig. } & \multirow{2}{*}{$\mathbf{T}$} & \multirow{2}{*}{ Gl } & \multirow{2}{*}{$\begin{array}{l}\text { Sig. } \\
\text { (bilat.) }\end{array}$} & \multirow{2}{*}{ Dx } & \multirow{2}{*}{ EDx } & \multicolumn{2}{|c|}{$95 \%$ conf. inter. to dif. } \\
\hline & & & & & & & & Inf. & Sup. \\
\hline AV & 8.343 & .018 & -.778 & 9 & .457 & -.09067 & .11659 & -.35441 & .17308 \\
\hline NAV & & & -.844 & 6190 & .430 & -.09067 & .10744 & -.35162 & .17029 \\
\hline
\end{tabular}

Wherein:

AV: Equal variances have been assumed.

NAV: No equal variances have been assumed.

Dx: Difference of means.

EDx: Typical error of the difference.

Similarly, Table 14 presents the confidence interval, which includes the difference in means, and given that the difference between the two means was -0.09067 , it is within the confidence interval, which allows accepting that the means of both samples are statistically equal, that is to say that there are no differences between the two samples in relation to their means.

\section{Simple linear regression}

Once the statistical explanation of each factor in the present investigation was carried out and after the contrast with the theoretical referents that are the basis of the study, it is convenient to show how quantum leadership is for co-development in private universities, for which the simple linear regression test was applied to calculate the goodness of fit $\left(\mathrm{R}^{2}\right)$ between the variables under study as shown in Table 15 .

TABLE 15. Goodness settings, model summary

\begin{tabular}{|c|c|c|c|c|}
\hline Model & $\mathbf{R}$ & $\mathbf{R}^{\mathbf{2}}$ & $\mathbf{R}^{\mathbf{2}}$ corrected & typical error of estimate \\
\hline 1 & $.579^{\mathrm{a}}$ & .335 & .298 & 8.93583 \\
\hline
\end{tabular}

The presented result indicates that the quantum leadership is present in co-development, because as the codevelopment increases, the quantum leadership exercised in it increases, in other words, the quantum leadership is found in $33.5 \%$ of the strategies for execution of co-development in private universities of the Maracaibo municipality. Consequently, it is considered a model with high adjustment to explain the behavior between variables.

\section{Quantum leadership model for co-development in private universities}

When taking into account the results of each variable and their respective components, we proceed to present the quantum leadership model for co-development in private universities in the Maracaibo municipality of Zulia-Venezuela state (Table 16).

TABLE 15. Results for the components variables

\begin{tabular}{|c|c|c|c|}
\hline Variable & Components & Results & analysis categories \\
\hline \multirow{2}{*}{ Quantum leadership } & Stages of quantum leadership & \multirow{2}{*}{4.64} & \multirow{2}{*}{ Highly realized } \\
\cline { 2 - 2 } & Quantum leadership condition & & \multirow{2}{*}{3.32} \\
Co-development & Types of co-development & Medically realized \\
\cline { 2 - 2 } & Steps of the co-development method & \\
\hline
\end{tabular}

\section{IV.CONCLUSION}

Once presented, analyzed and discussed the results of this work aimed at proposing quantum leadership for co-development in private universities, the researcher reaches the following conclusions, taking into account the tendency and forcefulness of the responses issued by the population subject to study:

To describe the stages of quantum leadership in private universities, it is concluded that these stages are present in the quantum leadership of these institutions, in the following scale of position according to the results obtained: experience, learning, action and finally creativity. Similarly, to identify the condition quantum leadership, it is concluded that in these institutions, the leader assumes the status of quantum leadership giving greater importance to the total acceptance, presence and ultimately talent. In order to characterize the type of codevelopment in private universities, it is concluded that in higher education institutions the most used codevelopment is internal, because it is a highly realized action compared to open co-development which is a practice slightly carried out by the leader of these universities. With respect to determining the steps of the co- 
development method, it is concluded that the leader presents the topic, puts into play the competence / practice knowledge, allows for reflection and self-evaluation, promotes the design of an action plan, and tracks the training received in the co-development of these units, which is a highly used experience within these institutions.

\section{REFERENCES}

[1] I. Bonn, "Developing strategic thinking as a core competency," Management Decision, vol. 39, issue 1, pp. 63-71, 2001.

[2] D. Acemoglu, and M. O. Jackson, "History, Expectations, and Leadership in the Evolution of Social Norms," Review of Economic Studies, Oxford University Press, vol. 82, issue 2, pp. 423-456, 2015.

[3] P. Daniels, "The Sustainable Management of the Mekong River Basin: Insights from Buddhism," Journal of the International Association of Buddhist Universities, vol. 6, pp. 47-61, 2015.

[4] J. Dinh, R. Lord, W. Garnder, J. Meuser, R. C. Liden, and J. Hu, "Leadership theory and research in the new millennium: current theoretical trends and changing perspectives," Leadership quarterly, vol. 25, issue 1, pp. 36-62, 2014.

[5] M. Sowcik, A. C. Andenoro, M. McNutt, and S. E. Murphy, Leadership 2050: Critical Challenges, Key Contexts, and Emerging Trends. Emerald Group Publishing, 2015.

[6] M. Picchio, "Is training effective for older workers?," IZA World of Labor, issue 121, 2015.

[7] M. Alles, Co-development: A new way of learning. Buenos Aires, Argentina: Granica Editorial, 2010.

[8] J. D. Ford, L. Ford, and B. Polin, "Leadership in the Conduct of Organizational Change: An Integrative View," Presentation at the Annual Meeting of the National Academy of Management, 2014.

[9] J. Fris, and A. Lazaridou, "An additional way of thinking about organizational life and leadership: the quantum perspective," Canadian Journal of Educational Administration and Policy, issue 48, pp. 1-29, 2006.

[10] M. Naderifar, M. Barkhordar, S. Nemati, A. Jalalodini, and F. Ghaljaei, "The role of quantum skills in conflict resolution in educational organizations: A review article," Journal of Advances in Medical Education (JAMED), vol. 1, issue 2, 17-25, 2016.

[11] G. Monsangini. (2007). Co-development: more than just a fad? [Online]. Available: http://www.rebelion.org/docs/46654.pdf

[12] E. Shabani, Introduction to research methods and report writing: A practical guide for students and researchers in social sciences and the humanities. Eugene, USA: Resource Publications, 2016.

[13] E. Babbie, The basics of social research, 5th ed.. Belmont, USA: Wadsworth Cengage Learning, 2011.

[14] W. Trochim, J. P. Donnelly, and K. Arora, Research Methods: The Essential Knowledge Base, 2nd ed.. Cengage learning, 2015.

[15] E. Cho, and S. Kim, "Cronbach's Coefficient Alpha: Well Known but Poorly Understood," Organizational Research Methods, vol. 18, issue 2, 207-230, 2014.

[16] P. Gioya, and J. Rivera, Less leaders, more leadership. Madrid, Spain: LID Editorial, 2008.

[17] C. Wahl, C. Scriber, and B. Bloomfield, On becoming a leadership coach: A holistic approach to coaching excellence, 1st edition. New York, USA: Palgrave McMillan, 2012.

[18] Ş.Ş. Erçetin, and E. A. Kayman, How to Be a Quantum Leader in an Intelligent Organization?, In: Banerjee S., Erçetin Ş. (eds) Chaos, Complexity and Leadership 2012 - Springer Proceedings in Complexity. Dordrecht, Netherlands: Springer, 2014.

[19] M. Alles, Development of Competition and Co-development. México D.F., México: Tecnológico de Monterrey., 2015.

[20] M. Alles, Dictionary of human resources terms. Buenos Aires, Argentina: Granica Editorial.

[21] M. Alles, Reconciling professional and personal life. Two looks: organizational and individual. Buenos Aires, Argentina: Granica Editorial.

[22] J. Cuevas, Quantum Leadership. When you change, everything changes. México D.F., México: Grijalbo Editorial, 2013.

\section{AUTHOR PROFILE}

Rafael Paz works as independent researcher. Mr. Paz completed his doctorate from Universidad Rafael Belloso Chacin (Venezuela). Mr. Paz completed his undergraduate

Raul J. Martelo works as full-time professor at the University of Cartagena (Colombia). Mr. Martelo completed his magister from Industrial University of Santander (Colombia). Mr. Martelo completed his undergraduate in Systems Engineering at the Industrial University of Santander.

Diofanor Acevedo Correa works as full-time professor in the University of Cartagena (Colombia). Dr. Acevedo completed his doctorate from University of Valle (Cali-Colombia). Mr. Acevedo completed his undergraduate in Food Engineering and Pharmaceutical Chemistry at the University of Cartagena. 